Corresponding Author: Khalid

A. Aljohani; email:

kajohani@taibahu.edu.sa

Received 06 September 2021

Accepted 02 December 2021

Published 31 December 2021

Production and Hosting by

Knowledge E

(c) Khalid A. Aljohani et

al.. This article is distributed under the terms of the

Creative Commons

Attribution License, which

permits unrestricted use and redistribution provided that the original author and source are credited.

Editor-in-Chief:

Prof. Mohammad A. M. Ibnouf

\section{Understanding Factors Contributing to Nurses' Intention to Care for COVID-19 Patients Using the Theory of Planned Behavior}

\section{Khalid A. Aljohani ${ }^{1}$, Mohammad S. Aljohani ${ }^{2}$, Maria Jocelyn B. Natividad ${ }^{2}$, Paul Reinald B. Gracia², and Ibtehal I. Qazanli ${ }^{3}$}

${ }^{1}$ Community Health Nursing Department. College of Nursing, Taibah University, Saudi Arabia

${ }^{2}$ Medical-Surgical Nursing Department. College of Nursing, Taibah University, Saudi Arabia

${ }^{3}$ Community Health Nursing, Ministry of Health, Saudi Arabia

ORCID:

Khalid A. Aljohani: https://orcid.org/0000-0003-3242-082X

\section{Abstract}

Background: Globally, the nursing community has lost several colleagues during the Coronavirus Disease 2019 (COVID-19) battle. One of the negative consequences of the disease is the pressure on healthcare services and demands that exceed the system's capacity to provide sufficient resources. Similarly, the experiences of care providers might trigger emotional and physical stress, which could affect the healthcare system's readiness to manage infectious outbreaks. This study was aimed at investigating nurses' intention to care for COVID-19 patients and determining factors contributing to their intentions to care at the Ministry of Health facilities in Saudi Arabia.

Methods: This descriptive cross-sectional survey design was used to recruit 336 nurses working in Al Madinah Ministry of Health hospitals where COVID-19 patients received medical and nursing care. The instrument was created following the framework of the Theory of Planned Behavior.

Results: Nurses' intention to care for COVID-19 patients was significantly correlated with their education level, nationality, knowledge about COVID-19, and nurses' exposure during their earlier education for emerging infectious diseases. Factors related to social pressure from friends, colleagues, and workplace administration support needed improvement. Examining the model fits through multiple regression revealed that the combination of six subscales - "attitude, subjective norms, perceived behavioral control, behavioral beliefs, normative beliefs, and control beliefs" accounted for a significant $(89 \%)$ variability of intention to care, $R^{2}=0.892$, adjusted $\mathrm{R}^{2}=0.793, F(6-329)=201, p \leq 0.000$.

Conclusion: Providing nursing education is the main predictor of higher nurses' intention to care for COVID-19 patients, it is imperative that nursing education courses should continue investing in enhancing nurses' capabilities in caring for COVID-19 patients. 


\section{Introduction}

\section{What is known?}

1. Theory of Planned Behavior is a reliable approach to explain nurses' intention to provide nursing care.

2. Caring for COVID-19 is a perceived challenge in terms of continuity and efficiency of nursing care.

\section{What is new?}

1. Continuing nursing education courses may enhance nurses' intention to care for emerging infectious diseases such as COVID-19.

2. Social influence from friends, colleagues, and workplace administration support may contribute to nurses' willingness to care for COVID-19 patients.

Emerging Infectious Diseases (EID) refers to infectious diseases that emerged during the past 30 years with the probability to increase in the future [1]. In the last two decades, the remarkable examples of EID are the Middle East Respiratory Syndrome Coronavirus (MERS-CoV), Severe Acute Respiratory Syndrome Coronavirus (SARS-CoV), and Ebola Virus Disease (EVD). These diseases are the outcomes of the interactions of biological, social, ecological, and technological factors [2]. The focus of this paper is Coronavirus Disease 2019 (COVID-19) that was caused by a coronavirus and affects respiratory functions. The disease is highly contagious affecting all age groups with increased severity risk for older people and patients with comorbidities. Corresponding with other countries, cases in Saudi Arabia are increasing steadily [3].

The disease is highly contagious. The international nursing community lost several members during the COVID-19 battle. Therefore, global initiatives to combat the infection should focus on protective measures to stop spreading the infection [4]. One of the diseases' negative consequences is the pressure on healthcare services demands that exceed the system's capacity to provide resources for care. Such pressure leads to unprecedented workload, anxiety, and depression on healthcare providers especially nurses [5]. International nursing literature revealed significant stress on nurses as frontline healthcare team members [6, 7]. In detail, nurses who care for patients with EIDs as part of their duties suffer from several negative psychological consequences including depression, anxiety, and post-traumatic stress response [5, 8]. Importantly, some nurses declined EID patients' care duties and quit their jobs resulting in risky consequences for the entire healthcare system [9]. 
Previous studies in Saudi Arabia were focused on knowledge and stress during the MERS-CoV epidemic crisis [7]. MERS epidemics have an effect on medical students' discernment and their psychological agony all through the epidemic, which further shows that female students had higher stress while two-thirds of the sample reported mild anxiety [10]. Furthermore, studies found that MERS's physiological effects on emergency department (ED) residents have made their colleagues afraid of cross-infection because of their tasks in the unit [11]. It was notable that $4 \%$ of the sample considered changing jobs. The major rationale for such a decision was their intention not to expose their families to infection.

As indicated by earlier studies, healthcare providers' experiences during EID outbreaks may trigger their stress and they might decide to leave their jobs, which in turn affects the healthcare system's readiness to manage infectious outbreaks. Searching the literature did not identify Saudi studies exploring these issues among nurses during the COVID-19 outbreak. This study aims to investigate nurses' intention to care for COVID19 patients and be part of the responding healthcare team in Saudi Arabia. In specific, the study question is: What factors could predict nurses' intention to care for COVID-19 patients at Saudi Arabian health facilities? The finding could influence policymakers, education sectors on potential interventions and policies to improve healthcare system readiness on EID outbreaks.

\section{Methods}

\subsection{Study design}

A descriptive cross-sectional survey design was utilized to recruit nurses working in Al Madinah Ministry of Health $(\mathrm{MOH})$ hospitals that were designated to provide medical and nursing care for COVID-19 patients. The inclusion criteria were nurses working in medical wards, intensive care units, and EDs, while the exclusion criteria were nurses with less than one year of experience and those who were not directly working with patients such as in nursing office staff. The total sample size was 337 calculated using Raosoft ${ }^{T M}$ with inputs as 5\% margin of error: 95\% confidence level adjusted to population size 2700; and 50-response distribution [12]. However, the target sample was 437 nurses taking into account the drop rate. 


\subsection{The study instrument}

The study instrument included three parts. First, sociodemographic data such as age, sex, education, marital status, living arrangement, work experience, position, and working units. Second, work experience and training related to COVID-19 consisting of fouritem questions: Do you have experience in caring for patients with COVID-19?; Have you been trained in the use of personal protective equipment?; Have you been trained on EID?; and Have you been trained in the care of COVID-19?

The last part comprised items using the Theory of Planned Behavior (TPB) framework to measure nurses' intention to care for COVID-19 patients. Before utilizing the instrument, researchers sought permission from the author who previously used it for the nurse caring for SARS patients' intention to care for SARS patients [5, 13]. However, due to differences in context, the researchers modified the instrument with the guidance of the original author's instructions to develop the constructs [14]

\subsection{Validity and reliability}

The modified bilingual instrument went through two phases of face validity followed by expert consultation. An academic nurse psychologist reviewed the instrument with a recommendation of minimal changes in the wording methods for five questions. Initial psychometric assessment of the instrument revealed an acceptable level with a pilot sample of 15 participants. However, TPB instruments recommendation suggested a minimum of 80 subjects to assess the instruments $[14,15]$. Therefore, the researchers applied further assessment utilizing the entire study sample. The result was confirmed by an overall instrument Cronbach alpha of 0.958. The instrument's subscales Cronbach's alpha were attitude (0.72); subjective norms (0.68); perceived behavioral control (0.89); intention (0.96); behavioral beliefs (0.73); normative beliefs (0.90); and control beliefs (0.91). These scores supported the instrument's ability to measure nurses' intention to care for COVID-19 patients [16].

The revised instrument consists of the components of TPB that are behavioral beliefs; normative beliefs; control beliefs; attitude; subjective norm; perceived behavioral control; and intention [14]. Participants answered the 35-item instrument based on sevenpoint Likert-type scale ranging from 1 (strongly disagree) to 7 (strongly agree). 


\subsection{Statistical analysis}

Descriptive statistics were used to identify participants' and instrument characteristics. $T$-test and one-way ANOVA tests were used to identify correlations between participants' characteristics and their overall scores. Statistical analysis was performed using SPSS v.20.

\section{Results}

In total, 417 nurses participated in the study with a response rate of $95 \%$. However, 336 were involved in this study after examining violations of the exclusion criteria and incomplete responses. Table 1 shows that females represented $82 \%$ of the participants and $54 \%$ were in their early career stage. Twenty-one percent of the sample did provide nursing care to COVID-19 patients, ninety-four had training on the use of Personal Protective Equipment (PPE) such as correct steps to wear protective gowns, claves, and masks. Similarly, $68 \%$ were knowledgeable about the disease.

Nurses' intention to care for COVID-19 patients was significantly correlated to their education level, nationality, COVID-19, and previous EID continuing education. Nurses with postgraduate qualifications had a higher intention to care $(M=5.98, S D=0.1 .54)$ than those with bachelor degrees $(M=4.93, S D=1.83)$ and diplomas $(M=4.83, S D$ $=2.03 ; \mathrm{F}=3.17 ; P=0.043$ ). Saudi nurses had higher intention to care for COVID-19 patients' mean score $(M=5.23, S D=1.98)$ than expatriate nurses $(M=4.79, S D=$ 1.79), $t=2.1 ; P=0.036$. From a continuing education standpoint, participants who had previously received COVID-19 education had higher mean intention to care ( $M=5.13$, $S D=1.72)$ than those who did not attend COVID-19 continuing education sessions ( $M=$ 4.72, $\mathrm{SD}=2.06) t=1.95, P \leq 0.051$. Similarly, nurses with previous EID education had a higher mean score $(M=5.20, S D=1.71)$ than those who did not $(M=4.46, S D=2.10), t=$ 3.41; $P=0.001$. Finally, the nursing position almost reached the significance level. Head nurses $(M=5.38, S D=1.72$ ) had higher intention to care than the in-charge nurses ( $M$ $=5.09, \mathrm{SD}=1.70)$ and staff nurses $(\mathrm{M}=4.83, \mathrm{SD}=2.03), F=2.82, P=0.060)$.

Descriptive results in Table 2 indicate that the highest subscales "dimensions" among the participants were attitudes toward caring for COVID-19 patients $(M=5.47, S D=1.26)$ and behavioral beliefs ( $M=5.24, S D=1.36)$. However, subjective norms such as social pressure from friends, colleagues, and workplace administration support did not support participants' caring for COVID-19 patients ( $M=3.83, S D=1.47$ ). Nevertheless, the overall mean indicated good support in caring for COVID-19 patients $(M=4.75, S D=1.29)$. 
TABLE 1: Participants and characteristics and intention to care correlations.

\begin{tabular}{|c|c|c|c|c|c|c|}
\hline \multirow[t]{2}{*}{ Variable } & \multirow[t]{2}{*}{ Categories } & \multirow[t]{2}{*}{$\mathbf{N}$} & \multirow[t]{2}{*}{$\%$} & \multicolumn{3}{|c|}{ Nurses' intention } \\
\hline & & & & $M \pm S D$ & $t / F$ & P-value \\
\hline \multirow[t]{2}{*}{ Gender } & Male & 61 & 18 & $4.67(2.14)$ & 0.137 & 0.17 \\
\hline & Female & 275 & 82 & 5.03 (1.81) & & \\
\hline \multirow[t]{3}{*}{ Age group (yr) } & $18-34$ & 183 & 54 & $5.04(1.82)$ & 1.5 & 0.223 \\
\hline & $35-44$ & 120 & 36 & $5.00(1.96)$ & & \\
\hline & $\geq 45$ & 33 & 10 & $4.43(1.82)$ & & \\
\hline \multirow[t]{2}{*}{ Marital status } & Married & 218 & 65 & $4.86(1.92)$ & 1.44 & 0.151 \\
\hline & Not married & 118 & 35 & 5.17 (1.78) & & \\
\hline \multirow{3}{*}{$\begin{array}{l}\text { Living } \\
\text { arrangements }\end{array}$} & Alone & 61 & 18 & 4.85 (1.96) & 1.03 & 0.355 \\
\hline & With family & 171 & 60 & $5.11(1.90)$ & & \\
\hline & With friends & 104 & 20 & $4.80(1.87)$ & & \\
\hline \multirow[t]{3}{*}{ Position } & Staff & 222 & 66 & $4.80(1.94)$ & 2.82 & 0.06 \\
\hline & In-charge & 37 & 11 & 5.09 (1.70) & & \\
\hline & Head nurse & 77 & 23 & $5.8(1.72)$ & & \\
\hline \multirow[t]{3}{*}{ Education } & Diploma/associat & $\mathrm{t} \in 82$ & 24 & $4.83(2.03)$ & 3.17 & 0.043 \\
\hline & Bachelor & 234 & 70 & $4.93(1.83)$ & & \\
\hline & Master & 20 & 6 & $5.98(1.54)$ & & \\
\hline \multirow[t]{3}{*}{ Experience } & 01-May & 87 & 26 & $5.01(1.86)$ & 0.043 & 0.958 \\
\hline & 06-Oct & 99 & 30 & 4.93 (1.81) & & \\
\hline & $\geq 11$ & 150 & 44 & 4.96 (1.94) & & \\
\hline \multirow[t]{2}{*}{ Nationality } & Saudi & 135 & 40 & 5.23 (1.98) & 2.1 & 0.036 \\
\hline & Expatriates & 201 & 60 & 4.79 (1.79) & & \\
\hline \multirow{2}{*}{$\begin{array}{l}\text { Caring for COVID- } \\
19\end{array}$} & Yes & 71 & 21 & $5.30(1.80)$ & 1.75 & 0.083 \\
\hline & No & 265 & 79 & 4.88 (1.89) & & \\
\hline \multirow[t]{2}{*}{ PPE training } & Yes & 316 & 94 & 4.99 (1.86) & 0.751 & 0.461 \\
\hline & No & 20 & 6 & $4.63(2.10)$ & & \\
\hline \multirow{2}{*}{$\begin{array}{l}\text { COVID-19 } \\
\text { education }\end{array}$} & Yes & 199 & 60 & $5.13(1.72)$ & 1.95 & 0.051 \\
\hline & No & 137 & 40 & $4.72(2.06)$ & & \\
\hline \multirow[t]{2}{*}{ EID education } & Yes & 229 & 68 & 5.20 (1.71) & 3.41 & 0.001 \\
\hline & No & 107 & 32 & $4.46(2.10)$ & & \\
\hline
\end{tabular}

Table 3 presents the relationship between the Theory of Planned Behavior variables. A positive correlation was evident between "intention" and "attitudes" $(0.724)$ indicating that the better the attitude, the more positive the intentions are. Strong positive correlations were also evident between "intention" and perceived behavioral control (0.808), behavioral beliefs $(0.765)$, normative beliefs $(0.700)$, and control beliefs $(0.663)$. 
TABLE 2: Subscales and overall estimations.

\begin{tabular}{|c|c|c|c|c|}
\hline Subscale & \#Items & Mean & SD & Min-Max \\
\hline Attitude & 5 & 5.47 & 1.26 & $4.43-6.00$ \\
\hline Subjective norms & 5 & 3.83 & 1.47 & $3.38-4.23$ \\
\hline $\begin{array}{l}\text { Perceived behavioral } \\
\text { control }\end{array}$ & 5 & 4.81 & 1.65 & $3.88-5.44$ \\
\hline Intention & 5 & 4.97 & 1.87 & $4.84-5.23$ \\
\hline Behavioral beliefs & 5 & 5.24 & 1.36 & $4.75-5.67$ \\
\hline Normative beliefs & 5 & 4.54 & 1.74 & $3.75-4.87$ \\
\hline Control beliefs & 5 & 4.39 & 1.79 & $4.19-4.50$ \\
\hline Overall & 35 & 4.75 & 1.29 & $3.38-6.00$ \\
\hline
\end{tabular}

TABLE 3: Correlation matrix for the study variables in the Theory of Planned Behavior $(N=336)$.

\begin{tabular}{ll|l|l|l|l|l|} 
& Attitudes & $\begin{array}{l}\text { Subjective } \\
\text { norms }\end{array}$ & $\begin{array}{l}\text { Perceived } \\
\text { behavioral } \\
\text { control }\end{array}$ & $\begin{array}{l}\text { Behavioral } \\
\text { beliefs }\end{array}$ & $\begin{array}{l}\text { Normative } \\
\text { beliefs }\end{array}$ & $\begin{array}{l}\text { Control } \\
\text { beliefs }\end{array}$ \\
\hline $\begin{array}{l}\text { Intention } \\
\text { Attitudes }\end{array}$ & 0.724 & 0.432 & 0.808 & 0.765 & 0.7 & 0.663 \\
\hline $\begin{array}{l}\text { Subjective norms } \\
\text { Perceived behav- }\end{array}$ & 1 & 0.347 & 0.614 & 0.664 & 0.586 & 0.49 \\
\hline $\begin{array}{l}\text { ioral control } \\
\text { Behavioral beliefs }\end{array}$ & 1 & 0.419 & 0.336 & 0.585 & 0.48 \\
\hline $\begin{array}{l}\text { Normative beliefs } \\
\text { Control beliefs }\end{array}$ & & 1 & 0.654 & 0.644 & 0.68 \\
\hline
\end{tabular}

*Significant at $p<0.001$.

On the other hand, a moderate positive correlation was present between attitude and subjective norms (0.347), normative beliefs (0.586), and control beliefs $(0.490)$, and strong positive correlation to perceived behavioral control (0.614) and behavioral beliefs (0.664). In general, the result reveals that the better the attitude, the better are the other tested subscales.

\section{Discussion}

This study aimed to answer the research of what factors could predict nurses' intention to care for COVID-19 patients at Saudi Arabian health facilities. Interestingly, a higher intention to care is evident among Saudi nurses. Participants showed good intention to provide direct care, assist, support team, accept any task, and take the challenge to provide nursing care for COVID-19 patients $(M=4.97)$. This result was higher than the studies presented in Korea (4.31) and Taiwan (3.45) among nurses caring for EID [5, 17]. 
Education was a critical factor in a higher intention to care among the participants. In detail, the study showed that higher education background was correlated to a better intention to care. Moreover, attending COVID-19 continuing education had also supported a higher intention to care. The results could guide education entities within the Ministry of Health $(\mathrm{MOH})$ to focus their efforts on providing the required education that will intensify nurses' commitment to care for clients with EID.

Interestingly, Saudi nurses showed a higher intention to care for COVID-19 patients than expatriate nurses. This could be a result of the nurses' commitment to their duty in serving the country during this critical time. The comparisons with international studies in this regard were not applicable due to the lack of the nationality variable. However, there is significant evidence supporting the government initiatives toward Saudization to ensure an effective healthcare system [18].

From the scientific contribution stand, the study development of a bilingual (EnglishArabic) instrument to measure nurses' intention to care for COVID-19 patients could offer a valuable contribution in the nursing field especially in the Middle East where countries have similar contexts. International studies showed that physical and psychological stress are the struggles of care providers that need to be taken care of $[19,20]$. TPB instruments were used widely to assess nurses' intention to provide care, use specific medical equipment, and adopt nursing behavior [17, 21]. According to Lee and Kang, a new instrument must be developed to compensate for the weaknesses of older instruments [5]. The recent instrument has fewer items than similar international instruments. Therefore, it may suit busy nurses during the EID outbreaks. Besides, the English-Arabic items support the direct adaptation of the instrument in different settings and populations. Moreover, it is more likely that health organizations who use the instrument will be able to target specific areas of improvement such as attitude and perceived behavioral control. The developed instrument showed higher psychometric properties than earlier ones $[5,9]$.

\subsection{Implication for nursing practice}

The study implication for nursing practice is twofold. First, the study results encourage nursing bodies to focus their efforts on designing and providing continuing nursing education courses in such a way that gives nurses confidence in managing COVID-19 cases. Similarly, organizational factors should be efficiently governed to provide a positive work environment that supports nurses' contribution to national health emergencies. The study provided a ready-to-use bilingual instrument (English-Arabic) supporting 
healthcare organizations in exploring the nurses' intention to care for COVID-19 patients and measuring contributing factors that may affect nursing care outcomes in such cases.

\subsection{Limitations and considerations for future work}

Utilizing an online questionnaire may increase the proportion of younger nurses' participation. The workplace location was not included in the independent variable in the study aims, however, it would be paramount to include this variable in forthcoming studies to differentiate their effect on the nurses' intention to care. Considering that it is the initial study to investigate factors contributing to nurses' intention to care for COVID19 patients in Saudi Arabia, this could form a foundation in building appropriate task force strategies to respond to infectious diseases and alleviate the tremendous demand on healthcare providers. The study outcomes could inform policymakers, educational organizations, and clinical leaders about underlying issues in the nurses' intention to care for COVID-19 patients.

\section{Conclusion}

The current study provided insights on nurses' intentions to care and its contributing factors, which could offer sturdy healthcare system support during the pandemic. As recommended by this paper, providing nursing education is the main predictor of enhanced nurses' intention to care for COVID-19 patients, healthcare organizations are encouraged to explore their nurses' concerns using the developed instrument, which is a public domain.

\section{Acknowledgments}

None.

\section{Ethical Considerations}

Permission to conduct the study was granted by the Nursing College Institutional Review Board, the researchers' affiliation. Data were collected through an online questionnaire using Survey monkey from the period of April-May, 2020. Study information was presented on the front page of the questionnaire with an invitation letter to participate. 


\section{Competing Interests}

The authors declare that they have no competing financial, professional, or personal interests that might have influenced the presentation of the work described in this study.

\section{Availability of Data and Material}

All relevant data of this study are available to any interested researchers upon reasonable request to the corresponding author.

\section{Funding}

This study was not funded by any agency/institution.

\section{References}

[1] Oaks Jr., S. C., Shope, R. E., and Lederberg, J. (Eds.). (1992). Emerging infections: microbial threats to health in the United States. National Academies Press.

[2] Daszak, P., Cunningham, A. A., and Hyatt, A. D. (2000). Emerging infectious diseases of wildlife-threats to biodiversity and human health. Science, vol. 287, no. 5452, pp. $443-449$.

[3] MOH. (2020). Novel Coronavirus: (COVID-19). Retrieved from: https://www.moh.gov. sa/en/HealthAwareness/EducationalContent/Corona/Pages/corona.aspx

[4] World Health Organization. (2020). Coronavirus disease 2019 (COVID-19): situation report, 51. WHO. Retrieved from: https://apps.who.int/iris/handle/10665/331475

[5] Lee, J. and Kang, S. J. (2020). Factors influencing nurses' intention to care for patients with emerging infectious diseases: Application of the theory of planned behavior. Nursing \& Health Sciences, vol. 22, no. 1, pp. 82-90.

[6] Xie, J., Tong, Z., Guan, X., et al. (2020). Critical care crisis and some recommendations during the COVID-19 epidemic in China. Intensive Care Medicine, vol. 46, pp. 837840.

[7] Khalid, I., Khalid, T. J., Qabajah, M. R., et al. (2016). Healthcare workers emotions, perceived stressors and coping strategies during a MERS-CoV outbreak. Clinical Medicine \& Research, vol. 14, no. 1, pp. 7-14. 
[8] Maunder, R. G., Lancee, W. J., Balderson, K. E., et al. (2006). Long-term psychological and occupational effects of providing hospital healthcare during SARS outbreak. Emerging Infectious Diseases, vol. 12, no. 12, pp. 1924-1932.

[9] Kim, J. S. and Choi, J. S. (2016). Factors predicting clinical nurses' willingness to care for Ebola virus disease囚infected patients: a cross囚sectional, descriptive survey. Nursing \& Health Sciences, vol. 18, no. 3, pp. 299-305.

[10] Al-Rabiaah, Abdulkarim, Temsah M.-H., Al-Eyadhy, A. A., et al. (2020). Middle East Respiratory Syndrome - Corona Virus (MERS-CoV) associated stress among medical students at a university teaching hospital in Saudi Arabia. Journal of Infection and Public Health, vol. 13, no. 5, pp. 687-691.

[11] Al Ghobain, M., Aldrees T., Alenezi, A., et al. (2017). Perception and attitude of emergency room resident physicians toward Middle East Respiratory Syndrome outbreak. Emergency Medicine International, vol. 2017, article 6978256.

[12] Raosoft. (2004). Sample size calculator. Retrieved from: http://www.raosoft.com/samplesize.html

[13] Yoo, H. R., Kwon, B. E., Jang, Y. S., et al. (2005). Validity and reliability of an instrument for the predictive nursing intention for SARS patient care. Journal of Korean Academy of Nursing, vol. 35, no. 6, pp. 1063-1071.

[14] Ajzen, I. (2002). Constructing a TPB questionnaire: conceptual and methodological considerations. Retrieved from: http://chuang.epage.au.edu.tw/ezfiles/168/1168/ attach/20/pta_41176_7688352_57138.pdf

[15] Ajzen, I. (2006). Constructing a theory of planned behavior questionnaire. Retrieved from: http://www.people.umass.edu/aizen/ tpb.html

[16] Fleiss, J. L. (2011). Design and analysis of clinical experiments (vol. 73). John Wiley \& Sons.

[17] Ko, N.-Y., Feng, M.-C., Chiu, D.-Y., et al. (2004). Applying the theory of planned behavior to predict nurses' intention and volunteering to care for SARS patients in southern Taiwan. The Kaohsiung Journal of Medical Sciences, vol. 20, no. 8, pp. 389-398.

[18] Alshmemri, M., Shahwan-Akl, L., and Maude, P. (2016). Job satisfaction of Saudi nurses working in Makkah region public hospitals, Saudi Arabia. Life Science Journal, vol. 13 , no. 12 , pp. $22-33$.

[19] Huh, S. (2020). How to train health personnel to protect themselves from SARS-CoV2 (novel coronavirus) infection when caring for a patient or suspected case. Journal of Educational Evaluation for Health Professions, vol. 17, no. 10. 
[20] Legido-Quigley, H., Mateos-García, J. T., Campos, V. R., et al. (2020). The resilience of the Spanish health system against the COVID-19 pandemic. The Lancet Public Health, vol. 5, no. 5, pp. e251-e252.

[21] Via囚Clavero, G., Guàrdia-Olmos, J., Gallart-Vivé E., et al. (2019). Development and initial validation of a theory of planned behavior questionnaire to assess critical care nurses' intention to use physical restraints. Journal of Advanced Nursing, vol. 75, no. 9, pp. 2036-2049. 